NASA Technical Memorandum 109119

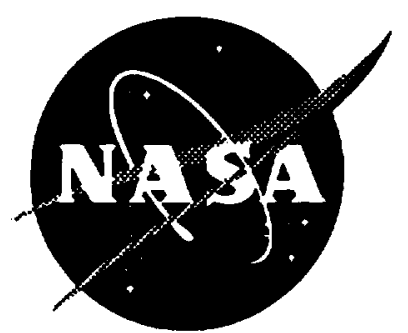

\title{
Variations of a Global Constraint Factor in Cracked Bodies Under Tension and Bending Loads
}

J. C. Newman, Jr. and J. H. Crews, Jr., and C. A. Bigelow Langley Research Center, Hampton, Virginia

D. S. Dawicke

Analytical Services and Materials, Inc., Hampton, Virginia

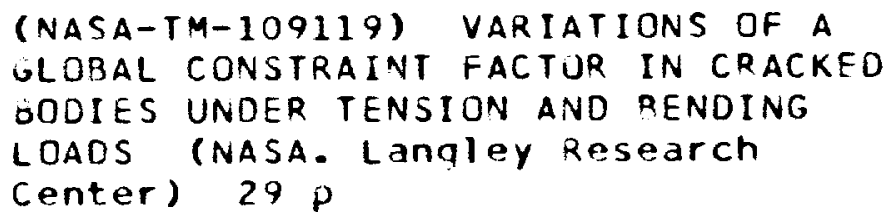

May 1994

National Aeronautics and

Space Administration

Langley Research Center

Hampton, Virginia 23681-0001 
- 


\title{
VARIATIONS OF A GLOBAL CONSTRAINT FACTOR IN CRACKED BODIES UNDER TENSION AND BENDING LOADS
}

\author{
J. C. Newman, Jr., J. H. Crews, Jr., and C. A. Bigelow \\ NASA Langley Research Center \\ Hampton, Virginia \\ and \\ D. S. Dawicke
}

Analytical Services and Materials, Inc.

Hampton, Virginia

\begin{abstract}
Elastic-plastic finite-element analyses were used to calculate stresses and displacements around a crack in finite-thickness plates for an elastic-perfectly plastic material. Middle- and edge-crack specimens were analyzed under tension and bending loads. Specimens were 1.25 to 20 $\mathrm{mm}$ thick with various widths and crack lengths. A global constraint factor $\alpha_{g}$, an averaged-normal-stress-to-flow-stress ratio over the plastic region, was defined to simulate three-dimensional (30) effects in twodimensional (2D) models. For crack lengths and uncracked ligament lengths greater than four times the thickness, the global constraint factor was found to be nearly a unique function of a normalized stress-intensity factor (related to plastic-zone-size-to-thickness ratio) from small- to large-scale yielding conditions for various specimen types and thickness. For crack-length-to-thickness ratios less than four, the global constraint factor was specimen type, crack length and thickness dependent. Using a 20 strip-yield model and the global constraint factors, plastic-zone sizes and crack-tip displacements agreed reasonably well with the 3D analyses. For a thin sheet aluminum alloy, the critical crack-tip-opening angle during stable tearing was found to be independent of specimen type and crack length for crack-length-to-thickness ratios greater than 4 .
\end{abstract}

\section{INTRODUCTION}

The importance of constraint effects in the failure analysis of cracked bodies has long been recognized by many investigators. Strain gradients that develop around a crack front cause the deformation in the 
local region to be constrained by the surrounding material. This constraint produces multiaxial stress states that complicate stress analyses and influence fatigue crack growth and fracture behavior. The level of constraint depends upon the crack configuration and crack location relative to external boundaries, the material thickness, the type and magnitude of applied loading, and the material stress-strain properties. In the last few years, a concerted effort by the fracture community (see refs. 1 and 2) has been undertaken to quantify the influence of constraint on fracture. To evaluate various constraint parameters, two- and three-dimensional (2D and 3D) stress analyses have been used to determine stress and deformation states for cracked bodies.

In the past, Levy, Marcal, and Rice [3], Kiefer and Hilton [4], de Lorenzi and Shih [5], and Moyer and Liebowitz [6] used 3D, small-strain, finite-element analyses to study cracked finite-thickness plates. Sih and Chen [7] used small-strain plasticity theory but departed from classical approaches by varying the tensile flow properties through the thickness. Brocks et.al [8] and Hom and McMeeking [9] used large-strain, finiteelement analyses to study the local stresses and deformations around a crack in finite-thickness plates. Similar analyses were also carried out by Wilkins [10] and Ayres [11] using finite-difference methods and by Malik and $\mathrm{Fu}$ [12] with the method of lines. These studies obtained plastic-zone shapes and stress distributions around the crack front for specific cracked specimens.

More recently, the T-stress (in-plane tangential stress parallel to the crack surfaces [13]), and the Q-stress (stress factor used to characterize the difference between actual stresses and the HRR stress field [14]) were used as parameters to predict the effects of in-plane constraint on fracture. Analyses by Brocks and Kunecke [15], and analyses and tests by Sommer and Aurich [16], on compact specimens and on surfacecracked plates showed how stable crack growth under monotonic loading varied with another constraint parameter, the mean-stress-to-equivalentstress ratio.

Fatigue-crack growth is also influenced by constraint variations around the crack front. A constraint parameter based on the normalstress-to-flow-stress ratio $\left(\sigma_{y y} / \sigma_{0}\right)$ has been used to characterize fatigue crack-growth and crack-closure behavior under cyclic loading [17]. In 
Newman et.al [18], a "global" constraint factor $\alpha_{g}$, the averaged-throughthe-thickness value of normal stress acting over the plastic region, was defined for use in 2D crack analyses to simulate 30 effects. Using the global constraint factors, the crack-tip-opening displacements from a modified Dugdale model [17] compared reasonably well with 30 finiteelement results from small- to large-scale yielding conditions [18]. The global constraint factor concept was also successfully applied to predict fatigue-crack growth in thin-sheet alloys under aircraft spectrum loading.

The capability to use fatigue-crack-growth and fracture properties from laboratory specimens to predict behavior of structural components depends upon the ability to calculate the constraint parameters and to determine their effects on critical values of appropriate crack-driving parameters $(K, J$ or $\delta)$. Unfortunately, parametric studies have not been conducted to establish the influence of crack configuration, thickness, crack length, applied stress level and material stress-strain properties on crack-front stresses, deformations, and constraint for standard laboratory specimens and structural components. Because of the complex stress fields, such studies must be conducted using 3D numerical stress analyses. From these analyses, expressions characterizing constraint need to be developed. Given a body with a through-the-thickness crack, equations need to be developed which express the crack-front constraint as a function of crack configuration, loading, and material properties as

$$
\text { Constraint }=f\left(c, w, B, S, E, \sigma_{0}, n\right)
$$

These expressions may be used to characterize fatigue-crack growth and fracture under various constraint conditions or they may be used in $2 \mathrm{D}$ models, such as the modified Dugdale model, to correlate and predict fatigue-crack growth [17] and fracture [19]. For use in 2D crack models, an averaged-through-the-thickness constraint factor may be required.

The objective of this paper is to present 3D elastic-plastic, finite-element results on the influence of crack length, width, thickness, and loading (tension and bending) on a global constraint factor for a straight-through crack in an elastic-perfectly plastic material. Standard laboratory (middle-crack, double-edge-crack and single-edge-crack) specimens were analyzed. Primarily monotonic loading with a stationary 
crack front was considered, but a thin specimen was also analyzed under stable tearing conditions. Comparisons are made between plastic-zone sizes and crack-tip-opening displacements calculated from a modified Dugdale (strip-yield) model and the 30 analyses to assess the capability of the model to simulate 3D effects. Constraint equations are developed which relate the global constraint factor to a normalized stress-intensity factor for crack-length- and uncracked-ligament-length-to-thickness ratios ( $C / B$ and $b / B$, respectively) greater than four. Constraint variations for $c / B$ ratios less than four are presented. Measurements made on the critical crack-tip-opening angle (CTOA) during stable tearing in a thinsheet aluminum alloy for various specimen types with $c / B$ ratios greater than four are also presented.

\section{NOMENCLATURE}

b Uncracked ligament length, mm

B Plate thickness, mm

c Crack length or half-length (see Fig. 1), mm

d Minimum element size in crack-front region, $\mathrm{mm}$

E Modulus of elasticity, MPa

h Plate half-height, $\mathrm{mm}$

$K \quad$ Mode I (two-dimensional) stress-intensity factor, MPa-/m

$\mathrm{J} J$ contour integral, $\mathrm{kN} / \mathrm{mm}$

M Applied moment, $\mathrm{Nm}$

$n$ Strain-hardening coefficient

S Applied stress, MPa

$\checkmark \quad$ Crack-opening displacements along crack surface, mm

$v_{0} \quad$ Crack-opening displacement at mid-plane, $\mathrm{mm}$

$w \quad$ Plate width or half-width (see Fig. 1), mm

$x, y, z$ Cartesian coordinates

$\alpha_{g}$ Global constraint factor (averaged $\sigma_{y y} / \sigma_{0}$ in plastic zone)

$\beta \quad$ Constant in constraint equation

$\gamma$ Constant in constraint equation

$\nu \quad$ Poisson's ratio

$\rho \quad$ Plastic-zone size, $\mathrm{mm}$

$P_{0} \quad$ Plastic-zone size at mid-plane, $\mathrm{mm}$

$\sigma_{\text {yy Normal (opening mode) stress, } \mathrm{MPa}}$ 
$\begin{array}{ll}\sigma_{0} & \text { Uniaxial flow stress, MPa } \\ \delta & \text { Crack-tip-opening displacement, } \mathrm{mm} \\ \psi_{C} & \text { Critical crack-tip-opening angle (CTOA), degrees }\end{array}$

\section{SPECIMENS TYPES AND MATERIAL}

Middle-crack tension, $M(T)$, double-edge-crack tension, $D E(T)$, and single-edge-crack bend, $S E(B)$, specimens were analyzed for thicknesses (B) ranging from 1.25 to $20 \mathrm{~mm}$ with crack-length-to-specimen-width ratio (c/w) of $0.3,0.5$ and 0.7 for widths ranging from 10 to $160 \mathrm{~mm}$, see Figure 1 . Plane-strain conditions were also imposed on some finite-element models to show limiting conditions. The material was assumed to be elasticperfectly plastic with properties typical of a high-strength aluminum alloy. The modulus of elasticity (E) was $70,000 \mathrm{MPa}$, the uniaxial flow stress $\left(\sigma_{0}\right)$ was $500 \mathrm{MPa}$, and Poisson's ratio $(\nu)$ was 0.3 . The finiteelement models were subjected to either monotonic or constant-K loading. Under monotonic loading, the crack front was held stationary, but under constant-K loading the crack front was grown uniformiy through the thickness by one element size at a time until the desired crack extension was achieved. The stress-intensity factor solutions were obtained from reference 20 .

\section{FINITE-ELEMENT ANALYSES}

A three-dimensional (3D), elastic-plastic, finite-element program, ZIP3D [21], developed at the NASA Langley Research Center, was used in this study. The program uses 8 -noded hexahedral elements, the von Mises yield criterion, isotropic hardening, small-strain deformation theory, and Drucker's associated flow rule. The elastic-plastic analysis is based on the initial-stress method and incremental theory of plasticity [22]. Crack extension under constant-K loading was modeled by a nodal-release procedure [23]. The finite-element formulation and solution method are given in reference 21 .

The 30 finite-element model, as shown in Figure 2, contained six layers through the half-thickness. The layer adjacent to the mid-plane of the specimen (along the $x-y$ plane) is denoted as Layer 1. Thicknesses of Layers 1 to 6 were $0.15,0.125,0.1,0.0625,0.0375$ and 0.025 of $B$, respectively. Figure 2 shows the model for a specimen with $c / w=0.5$. 
The width, height, and thickness of the model were scaled to the desired values. Region 1 shows the mesh refinement around the crack front. The smallest element size, $d$, in the crack-front region (Region 1) was $0.0008 w$. For $c / w$ ratios of 0.3 and 0.7 , the model shown in Figure 2 was modified by expanding or contracting elements in the regions $x<0.4 \mathrm{w}$ and $x>0.6 \mathrm{w}$ to achieve the required $c / w$ ratio. Thus, the region around the crack front was shifted but the element sizes and pattern were unchanged. All models had the same number of elements $(5,706)$ and nodes $(7,203)$. A uniform displacement was applied across the $y=h$ plane for the tension loaded specimens and a bending moment was applied on the bend specimen. In the incremental analysis, the displacement (or load) increment selected was thirty percent of the displacement (or load) required to yield the highest stressed element. Analyses of each specimen type were terminated when the plastic-yield region extended across the uncracked ligament.

\section{RESULTS AND DISCUSSION}

The "global" constraint factor $\alpha_{g}$ is defined as the average normalstress-to-flow-stress ratio for the elements in the plastic zone. In the following, the variations of $\alpha_{g}$ with applied loading for various cracked specimens is studied. Comparisons are made between plastic-zone sizes and crack-opening displacements calculated from the 30 analyses and from a 20 model using the constraint factors for stationary cracks. Constraint variations and local normal stresses were also calculated for a crack stably tearing in a thin-sheet material. To experimentally study specimen type effects on fracture, critical crack-tip-opening angles (СTOA) were measured during stable tearing in a thin-sheet aluminum alloy. The critical CTOA values are discussed in relation to the constraint factors calculated from the 30 analyses.

\section{Global Constraint Factor}

The global constraint factor was developed for use with existing 20 models $[17,19]$ of crack-growth behavior to simulate the effects of 30 stress states on plastic-zone sizes and crack-surface displacements. These models, which are based on a strip-yield model [24], require that a constant stress act in the tensile plastic zone. An average of the normal stresses in the plastic zone may be an appropriate value to estimate first-order constraint effects. The global constraint factor is 


$$
\alpha_{g}=\left(1 / A_{T}\right) \sum_{i=1}^{N}\left(\sigma_{y y} / \sigma_{0}\right)_{i} A_{i}
$$

where $A_{j}$ is the element area on the $y=0$ plane of a yielded element, $\left(\sigma_{y y} / \sigma_{0}\right)_{j}$ is the normalized normal stress for the element, and $A_{T}$ is the total area for all elements (N) which have yielded.

Even for an elastic-perfectly plastic material, the normal stresses in the plastic zone are not constant but vary with thickness, loading and distance from the crack front. To demonstrate the feasibility of using an average constraint factor for the distribution of normal stresses, a crack in an infinite plate was analyzed with the strip-yield model. This crack, shown in Figure 3, has a nonlinear stress distribution, similar to the 3D finite-element results (shown later), acting over the plastic zone. The stress distribution was assumed to be

$$
\sigma_{y y}=\sigma_{0}\left(\rho^{*} / \xi\right)^{m}
$$

where $\rho^{\star}$ is the plastic-zone size, $\xi$ is measured from the physical crack tip, and $m$ was selected to be 0.3 to give a nonlinear stress distribution. In the strip-yield analysis, the plastic zone was divided into a number of segments with a constant stress acting over each segment. The peak stress at the crack tip was 3 ; and the stresses dropped rapidly and approached unity at the end of the plastic zone. The average constraint factor from equation (2) was 1.4. The plastic-zone size, $\rho$, for $\alpha_{g}=1.4$ was about 80 percent of $\rho^{*}$. (The constraint factor $\alpha_{g}=1.8$ will be discussed later.)

Figure 4 shows comparisons among the crack-surface displacements computed from the strip-yield model for the nonl inear stress distribution (solid curve) and those from the model with $\alpha_{g}$ values of $1.4,1.8$ and 3 . Results for $\alpha_{g}=3$ underestimated both the crack-surface displacements and plastic-zone size $\left(\rho=0.2 p^{\star}\right)$. An $\alpha_{g}$ value of 1.8 was selected to match local crack-surface displacements but the plastic-zone size was still underestimated by a factor of 2 , as shown in Figure 3. An $\alpha_{g}$ value of 1.4 overestimated displacements (dotted curve) but gave a reasonable estimate for the plastic-zone size $\left(\rho=0.8 \rho^{\star}\right)$. To fit both plastic-zone sizes and crack-tip displacements, a two-parameter model would have been required. 
However, the objective of this paper is to characterize constraint with only one parameter. Thus, an averaged $\sigma_{y y} / \sigma_{0}$ was selected.

Stress States

From the FEM, the normal stresses, $\sigma_{y y}$, in the crack-front region normalized by flow stress, $\sigma_{0}$, are shown in Figures 5 and 6 for thick and thin specimens, respectively, subjected to tension and bending loads. The $M(T)$ half-width and $S E(B)$ width $(W)$ was $40 \mathrm{~mm}$, and the $\mathrm{c} / \mathrm{w}$ ratio for each was 0.5 . Element centroidal stresses along the crack $p l$ ane are plotted for Layer 1 (center) and the two outer layers as a function of $x / c$. The crack front is located at $x / c=1$. These results are shown for specific values of the normalized stress-intensity factor, $K /\left(\sigma_{0} / B\right)$, where $K$ is the 2D stress-intensity factor. (This normalized stress-intensity factor is proportional to the square-root of the plastic-zone-size-to-thickness ratio.) $K$ was calculated from the well-known formulas for the $M(T)$ and $\mathrm{SE}(B)$ specimens [20]. For the thick specimen (Fig. 5), the normal stress was high (about $2.7 \sigma_{0}$ for the $M(T)$ and $3.5 \sigma_{0}$ for the $S E(B)$ ) at the crack front for all layers except for the surface layer (Layer 6 ). However, in the thin-sheet material (Fig. 6), the stresses at the crack front were noticeably lower, indicating a lower local crack-front constraint. The central layers of the models showed the highest stresses and the slowest drop in stresses away from the crack front. The peak values of normal stress at the mid-plane and the stress variations through the thickness from the present analyses compared well with those from Kiefer and Hilton [4] and Moyer and Liebowitz [6].

The horizontal lines in Figures 5 and 6 show the global constraint factors, $\alpha_{g}$. For the thick material, $\alpha_{g}$ was lower for the $M(T)$ specimen than for the $S E(B)$ specimen $(C / B=1)$ but the constraint factors were nearly the same for the thin material $(C / B=16)$. As expected, the $\alpha_{g}$ values were lower for the thinner material indicating less constraint than the thicker material.

\section{Specimen Types}

The variation of $\alpha_{\mathrm{g}}$ with stress-intensity factor for a wide range of plate thicknesses ( $B=1.25$ to $20 \mathrm{~mm}$ ) and three specimen types is shown in Figures 7 and 8 for small and large widths, respectively. The c/w ratio for all specimens was 0.5 . (The stress-intensity factor was normalized by $\sigma_{0} / \mathrm{w}$ here because the $\mathrm{plane-strain}$ solutions are also shown.) The results 
from the plane-strain analyses appear to indicate upper limit solutions. The dash-dot line at $\alpha_{g}=1$ denotes a lower limit condition. For thicknesses less than $5 \mathrm{~mm}$ for the $40-\mathrm{mm}$ wide specimens and thicknesses less than $20 \mathrm{~mm}$ for the $160-\mathrm{mm}$ wide specimens (that is, $c / B \geq 4$ ), the $\alpha_{g}$ values were nearly independent of specimen type and showed the same variation with normalized $K$. For thicker $p l$ ates, the $M(T)$ specimen gave lower constraint factors than the $D E(T)$ and $S E(B)$ specimens. All curves, except for the $\mathrm{pl}$ ane-strain bend specimen, show a loss in global constraint as the applied $\mathrm{K}$ level (or equivalently the plastic-zone size) increases. The $p l a n e-s t r a i n$ solutions showed a much slower constraint loss with increasing $K$ level. For a given $K$ level, the thinner specimens gave the lowest constraint factors. Results for all specimen thicknesses tended to approach nearly the same constraint level (about 1.15) as largescale yielding conditions were reached. The rapid loss of constraint at $K /\left(\sigma_{0} / W\right)$ equal to about 0.9 for the $p l$ ane-strain $M(T)$ specimen was caused by the plastic region extending across the uncracked ligament. The flow stress used for these calculations was $500 \mathrm{MPa}$. Other calculations made with $\sigma_{0}$ equal to 300 and $700 \mathrm{MPa}$ for various thicknesses and the same width (not shown) demonstrated that the normalized stress-intensity factor $K /\left(\sigma_{0} / W\right)$ was able to collapse the results onto the same curves.

Because the global constraint factors were found to be nearly independent of specimen type for the thinner materials, as shown in Figures 7 and 8 , it was suspected that the crack-length-to-thickness ratio $(c / B)$ or the uncracked-ligament-length-to-thickness ratio $(b / B)$ were the controlling parameters. The constraint factors for all numerical results where $c / B$ and $b / B$ ratios are equal to or greater than 4 are shown in Figure 9. The constraint factor is plotted against a normalized stressintensity factor, $\mathrm{K} /\left(\sigma_{0} / \mathrm{B}\right)$, that is proportional to the square-root of the plastic-zone-to-thickness ratio. Plotting in this way, the results for all specimen types, thicknesses, widths, and crack-length-to-width ratios collapsed onto nearly a single curve. The upper dash-dot lines show the limiting results from the plane-strain analyses of the three specimen types. The plane-strain solutions are slightly dependent upon specimen type at low normalized stress-intensity factors. The lower limit appears to be about 1.15 and is nearly independent of specimen type. Results from the $M(T)$ specimens tended to suddenly drop towards unity when the yield 
region extended across the uncracked ligament (see results at $K /\left(\sigma_{0} / B\right) \approx$ 2,4 and 8). However, results from the SE(B) specimens showed a very slight rise during the development of the plastic hinge (see Fig. 10 at $K /\left(\sigma_{0} / B\right) \approx 2$ for $\left.C / B=4\right)$. The curves are from an equation chosen to fit the results for $c / B$ and $b / B \geq 4$. The constraint equation is

$$
\alpha_{g}=1.15+\beta e^{-\gamma K_{n}^{1.5}}
$$

where $K_{n}=K /\left(\sigma_{0} \sqrt{ } B\right), \beta=1.25$ and $\gamma=0.85$ for $M(T), \beta=1.4$ and $\gamma=0.95$ for $\operatorname{DE}(T)$, and $\beta=1.55$ and $\gamma=1.05$ for $\operatorname{SE}(B)$ specimens.

For $C / B$ and $b / B$ ratios less than 4 , the global constraint factors were found to be a function of specimen type, loading, thickness and width; and they were not uniquely related to normalized stress-intensity factor. Figures 10 and 11 show how the constraint factor varies with normalized stress-intensity factor for various widths and $\mathrm{c} / \mathrm{w}$ ratios, respectively, for a thick plate $(B=20 \mathrm{~mm})$. The open and solid symbols show the results for the $M(T)$ and $S E(B)$ specimens, respectively. The effects of specimen width are shown in figure 10 . The $S E(B)$ specimens produced higher constraint factors for smaller widths or lower $C / B$ ratios, whereas the $M(T)$ specimens showed a drop in constraint. The curves are from equation (4) and are for specimens with $c / B$ and $b / B$ ratios equal to or greater than 4 . For a given width $(w=40 \mathrm{~mm})$, the effects of $c / w$ ratios on constraint are shown in Figure 11 . The constraint factors for the bend specimen increased with $\mathrm{c} / \mathrm{w}$ ratios, whereas the results for the tension specimen showed very little influence of the $\mathrm{c} / \mathrm{w}$ ratio.

\section{Plastic-Zone Sizes}

The variation of the plastic-zone size through the thickness of a thin sheet and a thick $p l a t e M(T)$ specimen are shown in Figures 12 and 13, respectively. These figures show the normalized plastic-zone size $(\rho / c)$ along the $y=0 \mathrm{plane}$ plotted against $z / B(z=0$ is located at the midplane of the specimen). The symbols show the finite-element method (FEM) calculations for various values of $\mathrm{K} /\left(\sigma_{0} / \mathrm{w}\right)$ with $w=40 \mathrm{~mm}$. For the thinsheet material (Fig. 12), the plastic-zone size is largest near the free surface at low $K$ values. However, at higher $K$ values the maximum yield zone occurs in the middle of the specimen. But further loading causes the 
yield zone to become nearly uniform through the thickness. These results are in contrast to those expected, in that, the maximum plastic-zone size would have been expected to be at the free surface. The dashed lines denote the plastic-zone sizes calculated from the modified Dugdale model (MDM) [17] using the global constraint factors obtained from the 3D FEM. The calculated plastic-zone sizes are reasonable average values through the thickness.

Calculated plastic-zone sizes for a thick plate $(B=20 \mathrm{~mm})$ are shown in Figure 13 for several values of the normalized stress-intensity factor, $K /\left(\sigma_{0} / w\right)$. Again, the plastic-zone size is largest near the free surface at low $K$ values. However, for higher $K$ values the maximum yield zone moves inwards towards the specimen mid-plane. The dashed lines denote the plastic-zone size calculated from the MDM [17] using the global constraint factor (as shown). The calculated plastic-zone sizes are, again, reasonable average values through the thickness.

Figure 14 shows the plastic-zone size at the mid-plane of the $M(T)$ specimen normalized by crack length $\left(\rho_{0} / c\right)$ as a function of the normalized stress-intensity factor. The open symbols show the results for a wide range of thicknesses. A plane-strain analysis is also shown (solid symbols) for comparison. The $p l$ ane-strain results show a rapid increase in plastic-zone size at a normalized $K$ value of about 0.9 . The other thicknesses showed similar but less rapid transitions. These transitions in plastic-zone size with normalized $K$ for the finite-thickness specimens are associated with a rapid loss of out-of-plane constraint. Even the plane-strain solution exhibits an in-plane constraint loss when the yield region spreads across the uncracked ligament.

The curves in Figure 14 show the calculated plastic-zone sizes from the MDM [17] using values of the global constraint factor, $\alpha_{g}$, of 1 and 3 . These calculations tend to bound the plastic-zone sizes on the upper limit $\left(\alpha_{g}=1\right)$ and are reasonable approximations of the lower limit with an assumed plane-strain condition $\left(\alpha_{g}=3\right)$.

\section{Crack-Tip Displacements}

A comparison of normalized crack-tip-opening displacements $\left(v_{0} / c\right)$ at the mid-plane $(z / B=0)$ of an $M(T)$ and $S E(B)$ specimen as a function of the normalized stress-intensity factor, $K /\left(\sigma_{0} / W\right)$, is shown in Figure 15. 
These results are for the largest width $(w=160 \mathrm{~mm})$ specimen analyzed; and the $C / B$ and $b / B$ ratios were equal to or greater than 4 . Displacements were calculated very near the crack front (second node behind the crack front at $x / c=0.9968)$. The normalized stress-intensity factor correlated the 30 FEM displacements for both specimen types even as the plastic zone spread across the uncracked ligament. As expected, the thin specimen showed larger displacements than the thick specimen at the same normalized $K$ level. The solid curves show the calculated crack-tip-opening displacements (at $x / c=0.9968$ ) using the MDM [17] with $\alpha_{g}$ values calculated from equation (4). The effective flow stress in the MDM was $\alpha_{g}{ }^{\sigma}{ }_{0}$. The solid curves agree reasonably well with the finite-element results from small- to large-scale yielding conditions. The predicted $\mathrm{K}$ level at plastic collapse for the thick specimen was about 5 percent higher than the 3D FEM results. For comparison, the dotted curves show the calculated results from the MDM [17] for various constant values of $\alpha_{\mathrm{g}}$ from 1 to 3.

Figure 16 shows the crack-tip-opening displacement $\left(v_{0} / c\right)$ at the mid-plane of $M(T)$ specimens as a function of the normalized stressintensity factor. The $c / B$ and $b / B$ ratios for these specimens were 0,1 and 16 for the plane-strain case, the $20-\mathrm{mm}$ and $1.25-\mathrm{mm}$ thick specimens, respectively. The displacements, again, were calculated at the second node behind the crack front. The results from the FEM are shown for the thinnest and thickest plates analyzed (open symbols). The results for plane-strain conditions are shown as the solid symbols. For the same normalized stress-intensity factor, displacements were larger for the thinner specimen. As expected, the thinnest specimen had a lower constraint and, hence, had larger displacements near the crack front as compared to the thicker specimen. The plane-strain elastic solution is shown by the dash curve. Again, the solid curves show calculated cracktip-opening displacements (at $x / c=0.9968$ ) using the MDM [17] with the $\alpha_{g}$ values calculated from the 30 finite-element analyses (as shown by the solid curves in Fig. 7). The solid curves agree reasonably well with the finite-element results from small-to large-scale yielding conditions. Some differences were observed for the thick specimen for $K /\left(\sigma_{0} / \mathrm{W}\right)$ greater than 0.7. The upper and lower dotted curves in Figure 15 show the calculations from the MDM for $\alpha=1$ and 3 , the limiting conditions. At 
low values of $K /\left(\sigma_{0} / W\right)$, the FEM and MDM results approach the plane-strain solution. However, at high values of $K /\left(\sigma_{0} / \mathrm{W}\right)$, the FEM results show a loss of constraint. The vertical asymtote from the FEM results would have been predicted from the MDM using an $\alpha_{g}$ value of 1.1 for the thin specimen and 1.2 for the thick specimen.

The results shown in Figures 15 and 16 suggest that the global constraint factor controls the crack-surface displacements very near the crack front; and that the MDM can be used to model three-dimensional effects ( $p l$ astic-zone sizes and crack-surface displacements).

\section{Stably Tearing Cracks}

The previous analyses were made with stationary cracks. Because the normal stresses were extremely high in the crack front region even for thin-sheet materials, it was of interest to see how the local constraint effects, normal stresses, and crack-surface displacements were influenced by stable tearing. Analyses were conducted on a thin sheet $M(T)$ specimen where the crack was grown under constant-K conditions. In addition, results from previous studies on the influence of specimen type on critical CTOA values are presented and discussed in relation to the global constraint factors.

Analyses--Figure 17 compares the normal stresses for a stationary crack and a stably tearing crack in a thin sheet at the same normalized Kvalue. The final crack lengths for both cases is identical. The amount of stable crack growth was about equal to the sheet thickness. These results show that the normal stresses are not greatly affected by the plastic deformations left in the wake of the advancing crack. The normal stresses are somewhat lower in the interior region but approach the same normal stresses away from the crack front. These results suggest that the constraint effects (high normal stresses) are not greatly influenced by stable tearing and by the plastic-wake left along the crack surface.

Experiments--Photographic techniques have recently been developed to measure critical CTOA values during crack initiation and stable tearing in thin-sheet materials $[25,26]$. In one method, a high-resolution optical microscope was used to record images of the deformed crack surfaces during stable tearing. In each frame, the critical value of CTOA was measured at several locations $(0.3$ to $1.3 \mathrm{~mm}$ ) behind the crack tip. For each frame, 
the CTOA values were then averaged. In the second method, a digitalimaging correlation method [27] was used to record digitized images of speckle patterns around the crack-tip location. These two methods gave essentially the same CTOA values during stable tearing. A detailed description of these methods are given in Dawicke and Sutton [25].

Stable crack growth tests were conducted on three specimen types: middle-crack tension $M(T)$, compact tension $C(T)$, and three-hole-crack tension $T H(T)$ specimens. The standard laboratory specimens, $M(T)$ and $C(T)$, were selected to illustrate the influence of specimen type and loading on critical CTOA values. The TH(T) specimen was selected to measure CTOA in a structurally-configured specimen. This specimen has a stress-intensity factor solution similar to a cracked stiffened panel. All specimens were made of 2024-T3 aluminum alloy sheet material ( $B=2.3$ $\mathrm{mm})$. The critical CTOA values measured on these specimens are shown in Figure 18. The critical angle $\psi_{c}$ is plotted against crack extension, $\Delta c$ (visual measurements on surface of specimens). For each increment of crack extension, several values of $\psi_{c}$ were measured and the average is plotted. The initial fatigue crack surfaces were flat and showed a small amount of tunneling in the interior. During the early stage of stable tearing, however, the crack front exhibited severe tunneling in the interior $(\Delta C \approx B)$ and the crack surfaces were still relatively flat. The vertical line indicates the approximate location were the crack surfaces had completed the transition from flat to shear mode fracture (45 degree slant through the thickness). The $\psi_{c}$ values measured during crack initiation were high but dropped sharply during crack extensions equal to about the sheet thickness. Afterwards, the critical angle appeared to level off between 5 to 7 degrees. The solid horizontal line is the $\psi_{c}$ value ( 6 degrees) determined from finite-element analyses [28] to fit the maximum failure loads on several $M(T)$ test specimens. Newman et.al [28] determined that the high CTOA values found during crack initiation were due to the crack-front shape (severe tunnelling in the interior) and the large plastic deformations on the specimen surface (recorded with the photographic methods). Tests conducted in reference 28 were on relatively 1 arge specimens; and the $C / B$ and $b / B$ ratios were greater than 4 . These test results demonstrate that the critical CTOA is independent of specimen 
type, if the $C / B$ or $b / B$ conditions are met, and further confirm the global constraint factor results shown in Figure 9.

\section{CONCLUSIONS}

Three-dimensional, elastic-plastic (small-strain), finite-element analyses were used to study the stresses and deformations around a straight-through crack in finite-thickness plates for an elastic-perfectly plastic material. Three specimen types: middle-crack tension $M(T)$, double-edge-crack tension $D E(T)$, and single-edge-crack bend $S E(B)$ were analyzed for thicknesses ranging from 1.25 to $20 \mathrm{~mm}$ and widths ranging from 10 to $160 \mathrm{~mm}$. Plane-strain solutions were also obtained. For most analyses, the crack front was held stationary, but for a thin-sheet material the crack front was stably torn. A "global" constraint factor, an averaged-through-the-thickness value of normal stress to flow stress ratio $\left(\sigma_{y y} / \sigma_{0}\right)$ in the plastic zone (denoted $\left.\alpha_{g}\right)$, was defined for use with a strip-yield model. Plastic-zone sizes and crack-opening displacements near the crack front were compared with predictions from a strip-yield model for various thicknesses and applied stress levels. The results of this study support the following conclusions:

(1) The global constraint factor, $\alpha_{g}$, is nearly a unique function of a normalized stress-intensity factor, $K /\left(\sigma_{0} / B\right)$, for various cracked specimen types, widths, and thicknesses when the crack-length-tothickness (C/B) and uncracked-ligament-length-to-thickness (b/B) ratios are greater than 4 . An equation relating $\alpha_{g}$ and $K /\left(\sigma_{0} / B\right)$ was developed for $c / B$ and $b / B$ ratios greater than or equal to 4 .

(2) For $\dot{c} / B$ (or b/B) less than 4, the global constraint factor drops for $M(T)$ specimens and rises for $S E(B)$ specimens as the $c / B$ (or $b / B$ ) ratio decreases.

(3) Using a strip-yield model and the global constraint factors (from finite-element analyses or the equation), the plastic-zone sizes and crack-tip displacements for the $M(T)$ specimen agreed reasonably well with 30 finite-element results for various thicknesses. 
(4) From the finite-element analyses, the maximum plastic-zone size at the crack front and along the crack plane occurs in the interior of the specimen (away from the free surface) for both thin and thick specimens.

(5) Local normal stresses, $\sigma_{y y}$, are slightly reduced for tearing cracks in a thin sheet compared to those calculated for a stationary crack.

(6) For a thin sheet aluminum alloy, the critical crack-tip-opening angle (СTOA) is constant and is independent of specimen type after a small amount of crack extension ( $C / B$ and $b / B$ ratios greater than 4 ).

\section{REFERENCES}

[1] B1 auel, J. G. and Schwalbe, K. -H., Eds., Defect Assessment in Components - Fundamentals and Application, ESIS/EGF 9, Mechanical Engineering Publications, Ltd., 1991.

[2] Hackett, E., Schwalbe, K. -H. and Dodds, R., Eds., Constraint Effects in Fracture, ASTM STP 1171, 1993.

[3] Levy, N., Marcal, P. V. and Rice, J., "Progress in Three-Dimensional Elastic-Plastic Stress Analysis for Fracture Mechanics, "Nuclear Engineering Design, Vol. 17, 1971, pp 64-75.

[4] Kiefer, B. V. and Hilton, P. D., "Three-Dimensional Finite Element Analysis of Elastic-Plastic Crack Problems," Journal of Pressure Vessel Technology, Vol. 103, 1981, pp 214-218.

[5] de Lorenzi, H. G. and Shih, C. D., "3-D Elastic-Plastic Investigation of Fracture Parameters in Side-Grooved Compact Specimen, " International Journal of Fracture, Vol. 21, 1983, pp 195-220.

[6] Moyer, E., Jr. and Liebowitz, H., "Effect of Specimen Thickness on Crack Front Plasticity Characteristics in Three Dimensions," Advances in Fracture Research (Fracture 84), Pergamon Press, 1986, pp 889-896.

[7] Sih, G. C. and Chen, C., "Non-self-similar Crack Growth in ElasticPlastic Finite Thickness Plate," Theoretical and Applied Fracture Mechanics Journal, Vol. 3, 1985, pp 125-139.

[8] Brocks, W., Muller, W. and 0lschewski, J., "Experiences in Applying ADINA to the Analysis of Crack Tip Fields in Elastic-Plastic Fracture Mechanics," Computers and Structures Journal, Vol. 21, 1985, pp 137158. 
[9] Hom, C. L. and McMeeking, R. M., "Large Crack Tip Opening in Thin Elastic-Plastic Sheets," International Journal of Fracture, Vol. 45, 1990, pp 103-122.

[10] Wilkins, M. L., "Calculation of Elastic-Plastic Flow," Report TID4500, UC 34, Lawrence Livermore Laboratory, 1969.

[11] Ayres, D. J., "A Numerical Procedure for Calculating Stress and Deformation Near a Slit in a Three-Dimensional Elastic-Plastic Solid," Engineering Fracture Mechanics, Vol. 2, 1970, pp 87-106.

[12] Malik, S. N. and Fu, L. S., "Elasto-Plastic Analysis for a Finite Thickness Rectangular Plate Containing a Through-Thickness Central Crack," International Journal of Fracture, Vol. 18, 1982, pp 45-63.

[13] Hancock, J. W., Reuter, W. G. and Parks, D. M., "Constraint and Toughness Parameterised by $T$, " Constraint Effects in Fracture, ASTM STP 1171, E. Hackett, K. -H. Schwalbe, and R. Dodds, Eds., 1993, Pp 21-40.

[14] O'Dowd, N. P. and Shih, C. F., "A Family of Crack Tip Fields Characterized by a Triaxiality Parameter, " Journal of Mechanics and Physics of Solids, Vol. 39, 1992, pp 989-1015.

[15] Brocks, W. and Kunecke, G., "On the Influence of Triaxiality of the Stress State on Ductile Tearing Resistance," Defect Assessment in Components - Fundamentals and Appl ications, ESIS/EGF 9, J. G. Blauel and K. -H. Schwalbe, Eds., Mechanical Engineering Publication, 1991, pp 189-201.

[16] Sommer, E. and Aurich, D., "On the Effect on Constraint on Ductile Fracture," Defect Assessment in Components - Fundamentals and Applications, ESIS/EGF 9, J. G. Blauel and K. -H. Schwalbe, Eds., Mechanical Engineering Publication, 1991, pp 141-174.

[17] Newman, J. C., Jr., "A Crack-Closure Model for Predicting Fatigue Crack Growth under Aircraft Spectrum Loading," Methods and Models for Predicting Fatigue Crack Growth under Random Loading, ASTM STP 748, J. B. Chang and C. M. Hudson, Eds., 1981, pp 53-84.

[18] Newman, J. C., Jr., Bigelow, C. A. and Shivakumar, K. N., "ThreeDimensional Elastic-Plastic Finite-Element Analyses of Constraint Variations in Cracked Bodies," Engineering Fracture Mechanics, Vol. 46, No. 1, 1993, pp 1-13.

[19] Newman, J. C., Jr., "Prediction of Stable Crack Growth and Instability Using the $V_{B}$-Curve Method," Elastic-Plastic Fracture Mechanics Technology, ASTM STP 896, J. C. Newman, Jr. and F. J. Loss, Eds., 1985, pp 139-166.

[20] Tada, H., Paris, P. C. and Irwin, G. R., "The Stress Analysis of Cracks Handbook," Del Research Corporation, 1985. 
[21] Shivakumar, K. N. and Newman, J. C., Jr., "ZIP3D - An Elastic and Elastic-Plastic Finite-Element Analysis Program for Cracked Bodies," NASA TM 102753, 1990.

[22] Zienkiewicz, 0. C., Valliappan, S., and King, I. P., "Elasto-Plastic Solutions of Engineering Problems, Initial Stress, Finite-Element Approach, " International Journal Numerical Methods in Engineering, Vol. 1, 1969, pp 75-100.

[23] Chermahini, R. G., Shivakumar, K. N. and Newman, J. C., Jr., "ThreeDimensional Finite-Element Simulation of Fatigue Crack Growth and Closure," Mechanics of Fatique Crack Closure, ASTM STP 982, J. C. Newman, Jr. and W. Elber, Eds., 1988, Pp 398-413.

[24] Dugdale, D. S., "Yielding of Steel Sheets Containing Slits, "Journal of Mechanics and Physics of Solids," Vol. 8, 1960, pp 100-104.

[25] Dawicke, D. S. and Sutton, M. A., "Crack-Tip Opening Angle Measurements and Crack Tunneling under Stable Tearing in Thin sheet 2024-T3 Aluminum Alloy," NASA CR-191523, September 1993.

[26] Dawicke, D. S., Sutton, M. A., Newman, J. C., Jr. and Bigelow, C. A., "Measurement and Analys is of Critical CTOA for an Aluminum Ailoy Sheet," NASA TM 109024, September 1993.

[27] Sutton, M. A., Bruck, H. A. and McNeill, S. R., "Determination of a Computer Vision Methodology for the Analysis of Surface Deformation in Magnified Image," Experimental Mechanics, Vol. 29, No. 3, 1989, pp 261-267.

[28] Newman, J. C., Jr., Dawicke, D. S. and Bigelow, C. A., "FiniteElement Analyses and Fracture Simulation in Thin-Sheet Aluminum Alloy," Durability of Metal Aircraft Structures, Atlanta Technology Publications, Atlanta, GA, 1992, pp 167-186. 


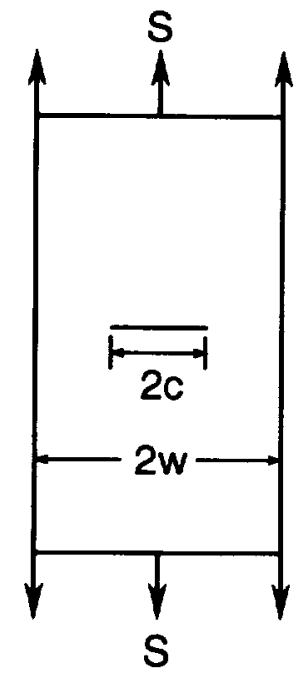

(a) $M(T)$

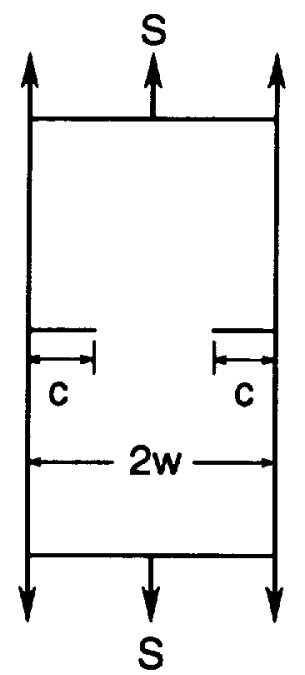

(b) $\mathrm{DE}(\mathrm{T})$

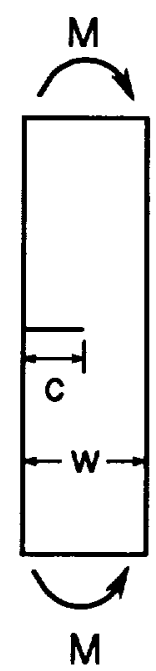

(c) $S E(B)$

FIG. 1--Specimen types analyzed for finite-thickness plates.

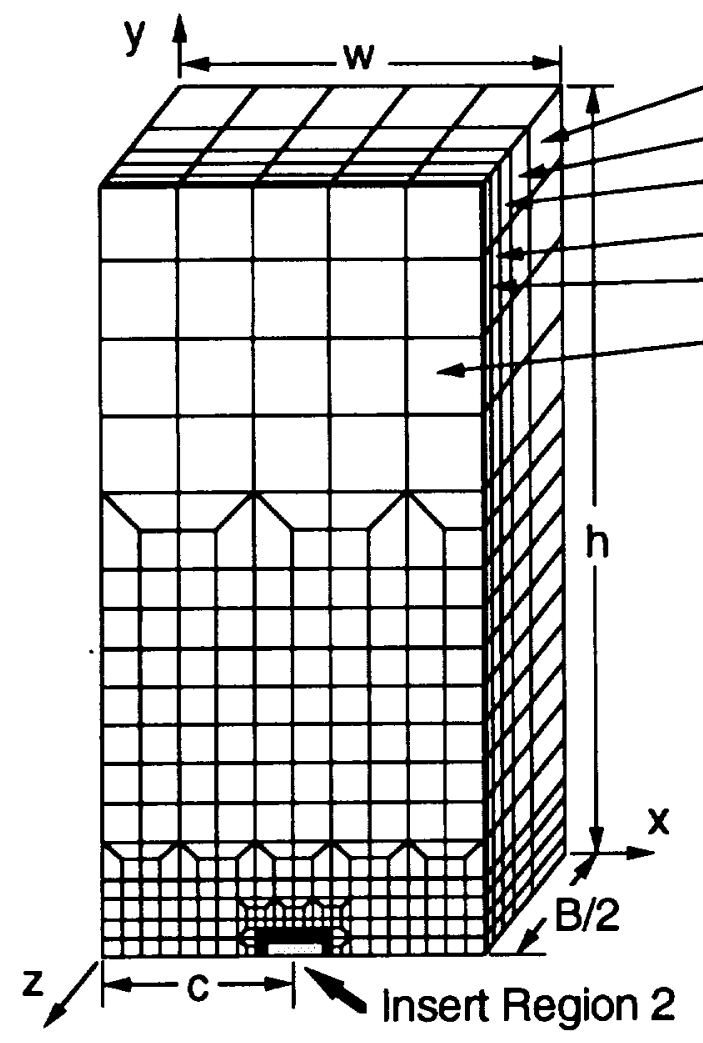

Layer 1

Elements $=5706$

Nodes $=7203$

Region 1

Region 2

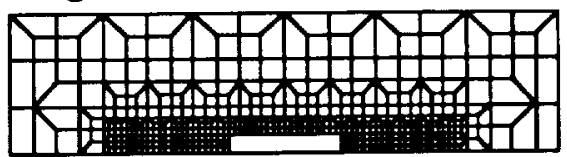

FIG. 2--Finite-element model of cracked specimen with $c / w=0.5$. 


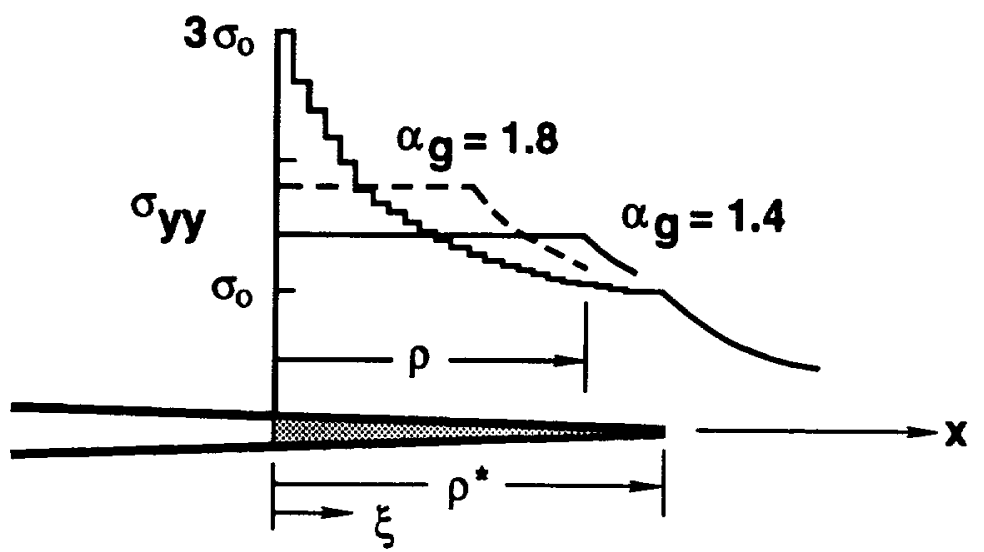

FIG. 3--Nonlinear- and constant-stress distributions for strip-yield model.

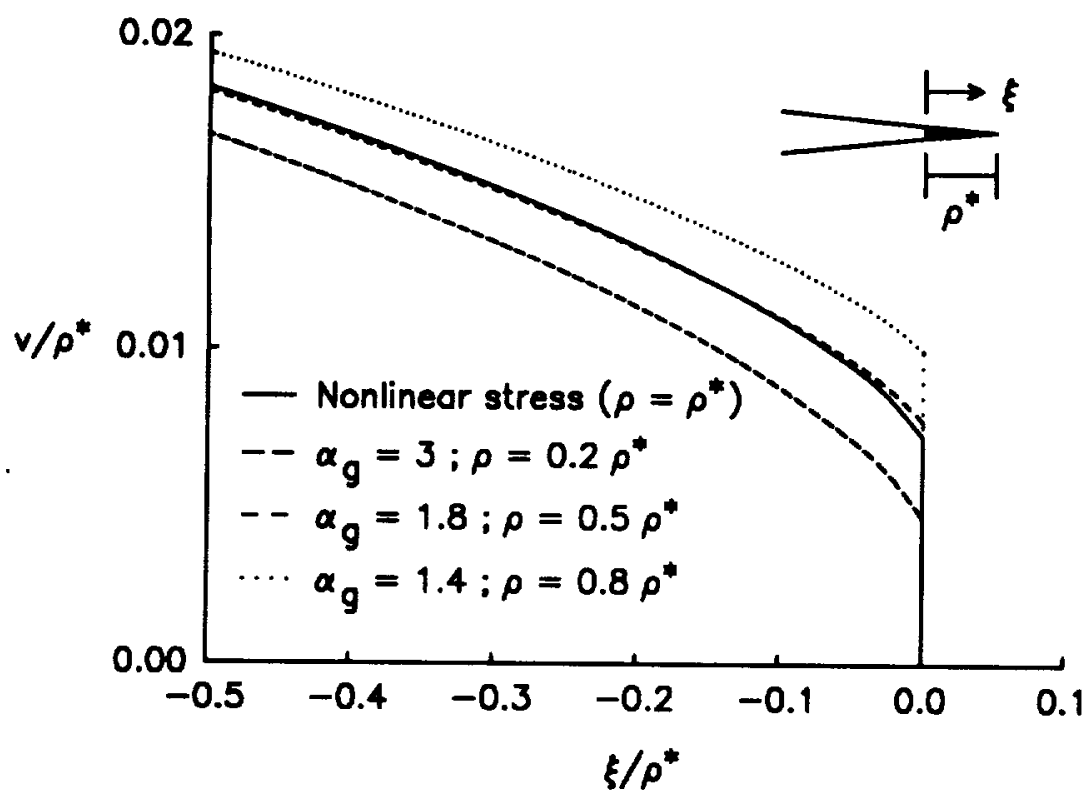

FIG. 4--Comparison of near crack-tip displacements from strip-yield model for nonlinear- and constant-stress distributions. 


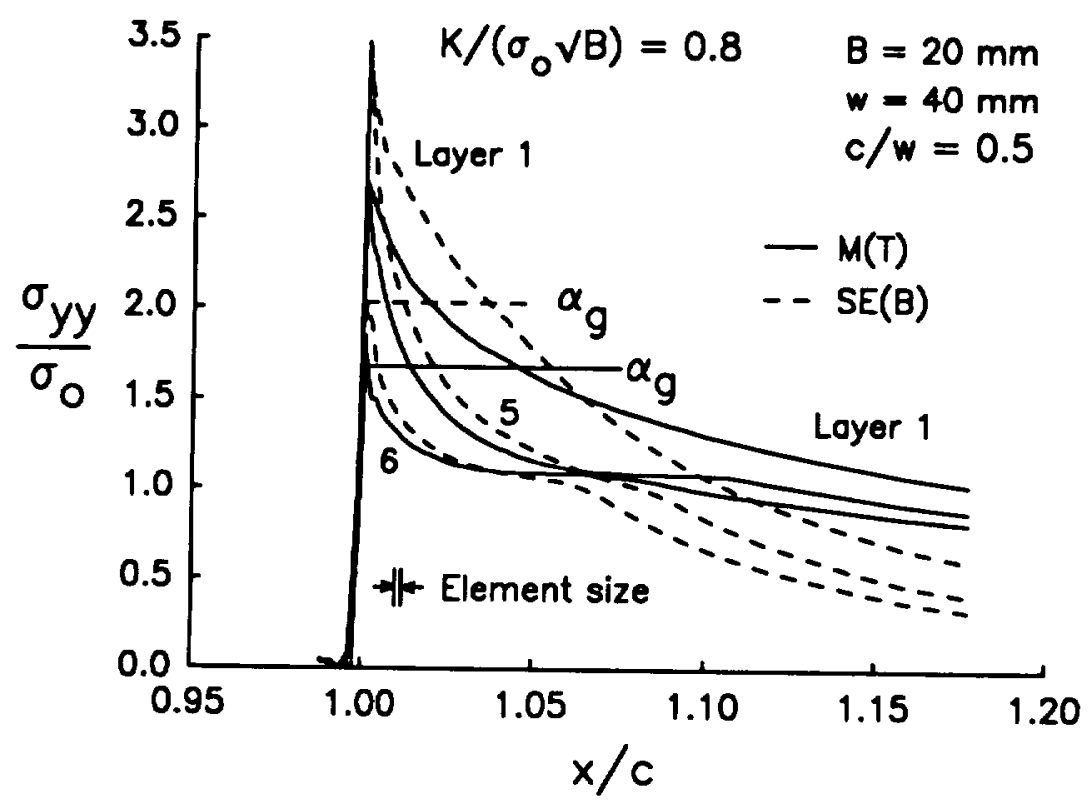

FIG. 5--Normal stresses near the crack front in thick plate under tension and bending loads.

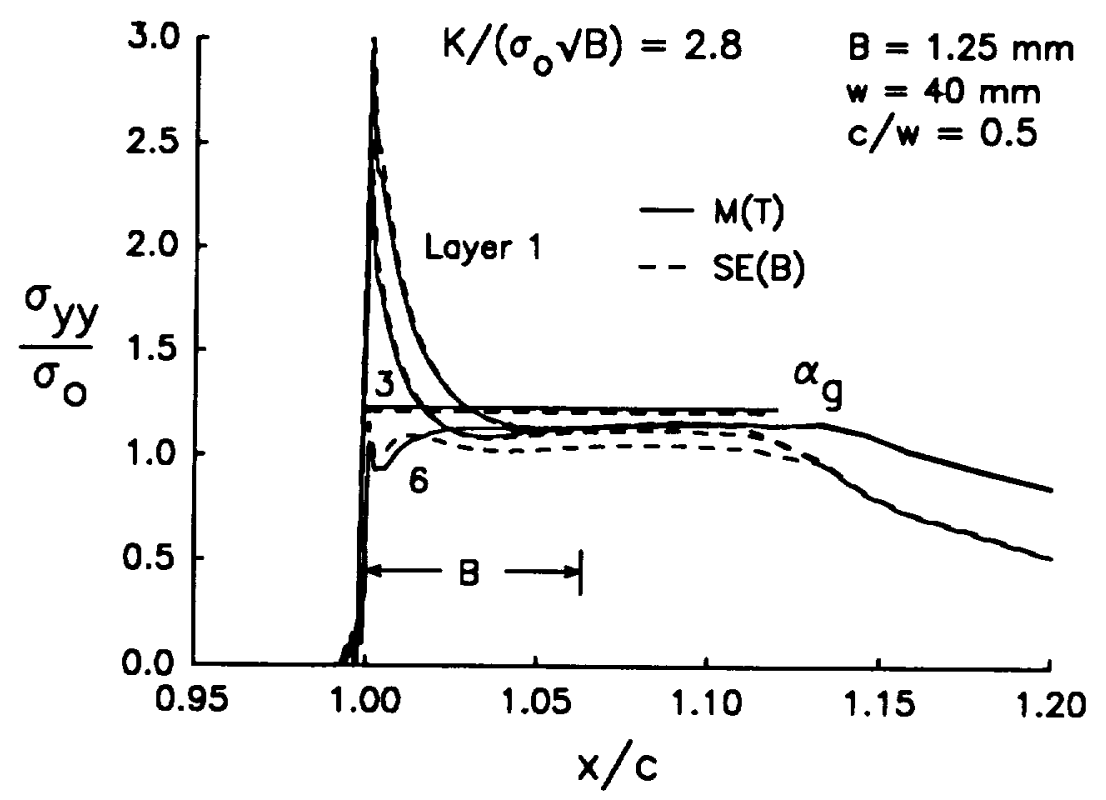

FIG. 6--Normal stresses near the crack front in thin sheet under tension and bending loads. 


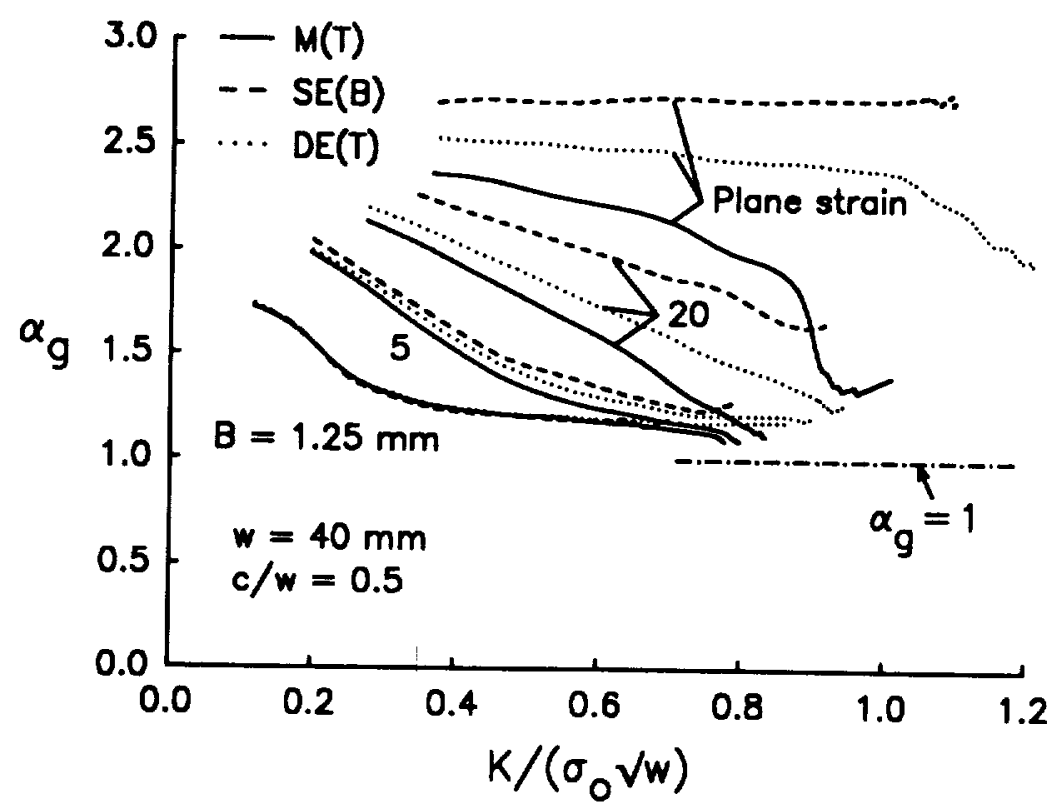

FIG. 7--Global constraint factors for various specimen types and thicknesses with small width $(w=40 \mathrm{~mm})$.

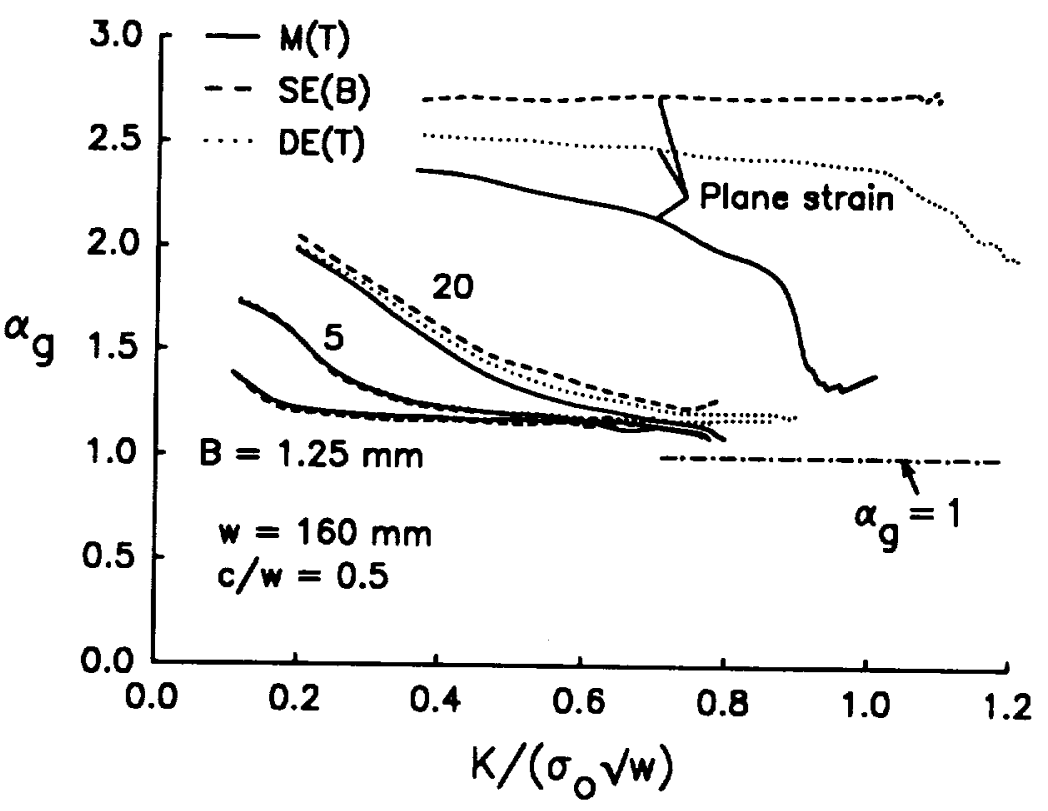

FIG. 8--Global constraint factors for various specimen types and thicknesses with large width $(w=160 \mathrm{~mm})$. 


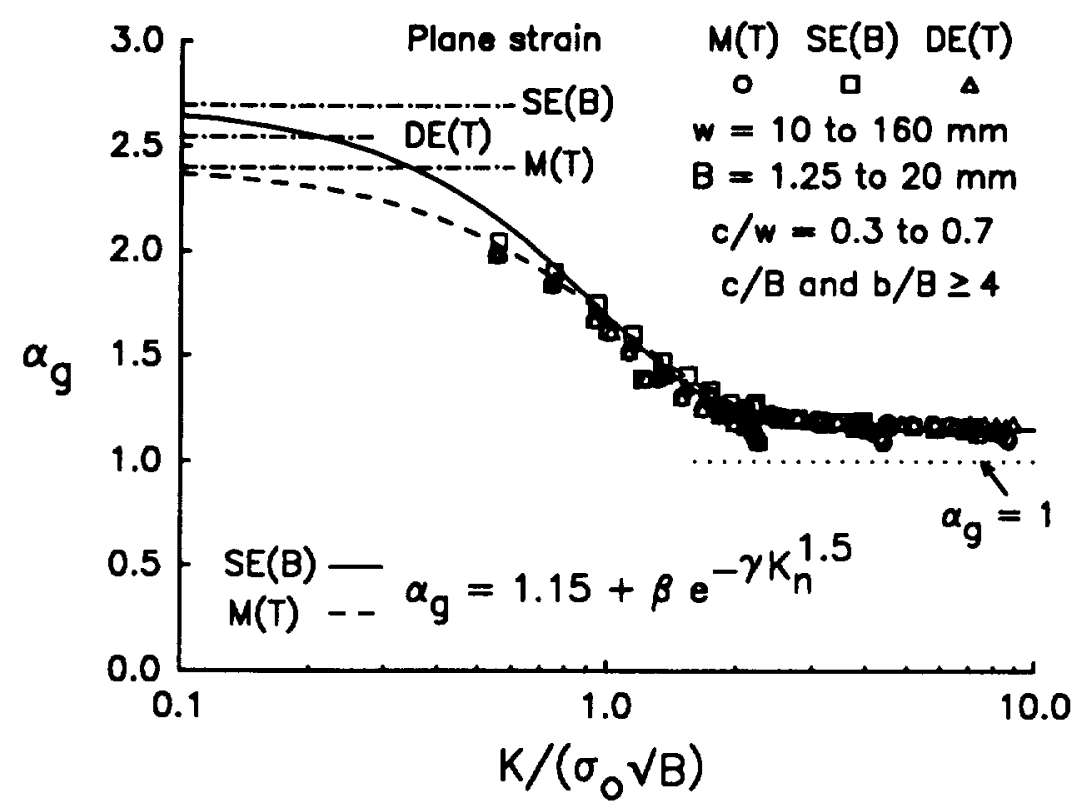

FIG. 9--Global constraint factors for various specimen types with $C / B$ and $b / B$ ratios greater than 4.

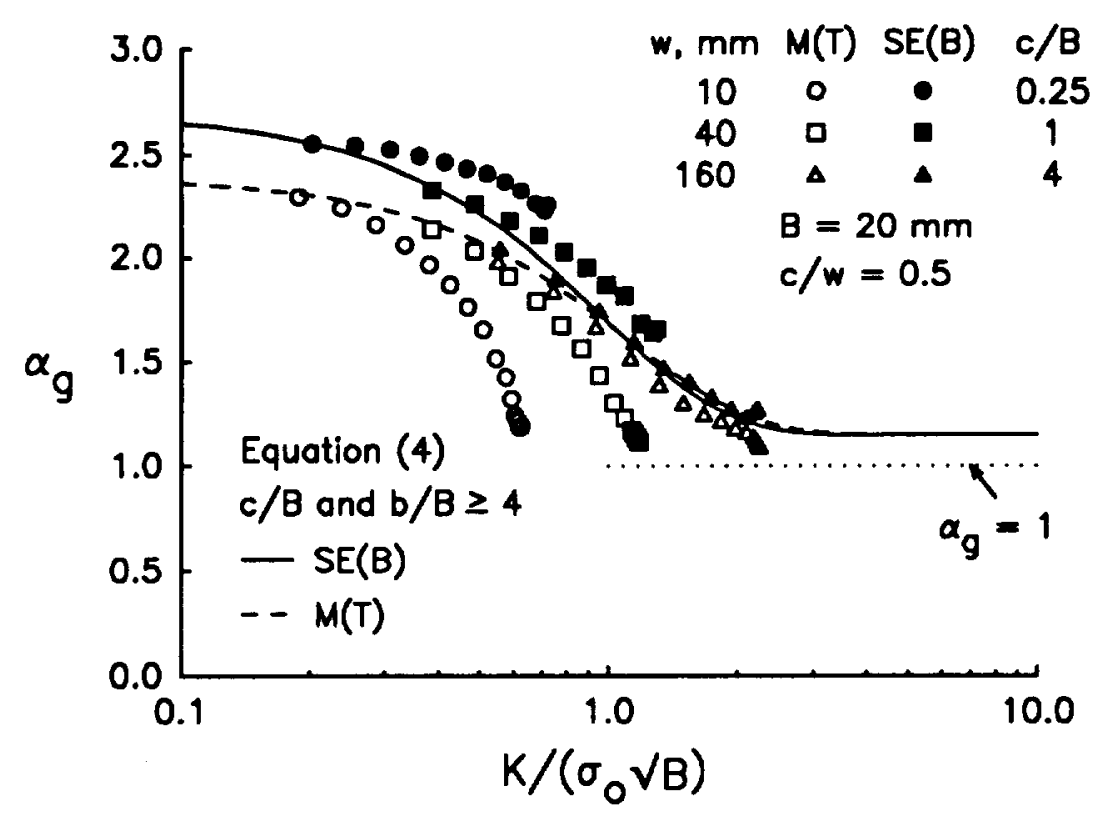

FIG. 10--Global constraint factors for a thick plate with various widths and $C / B$ ratios less than or equal to 4. 


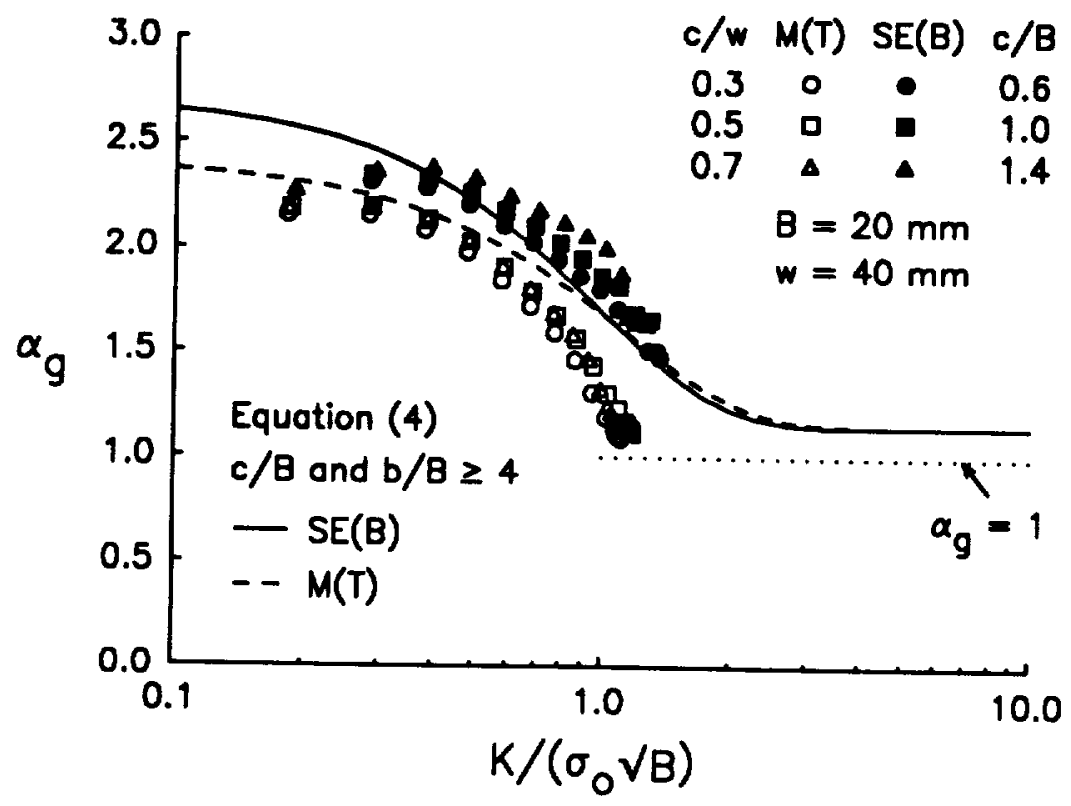

FIG. 11--Global constraint factors for a thick plate with various $\mathrm{c} / \mathrm{w}$ ratios.

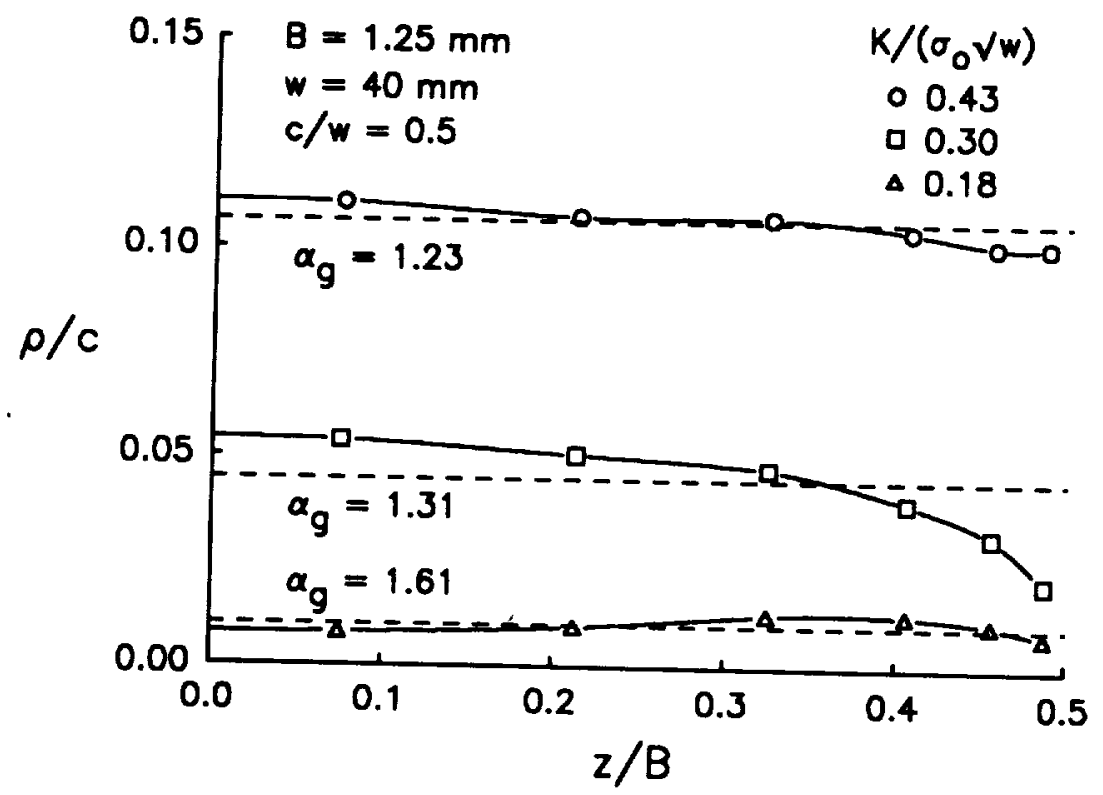

FIG. 12--Plastic-zone size through the thickness for various $K /\left(\sigma_{0} / w\right)$ levels for an $M(T)$ thin sheet with $c / w=0.5$. 


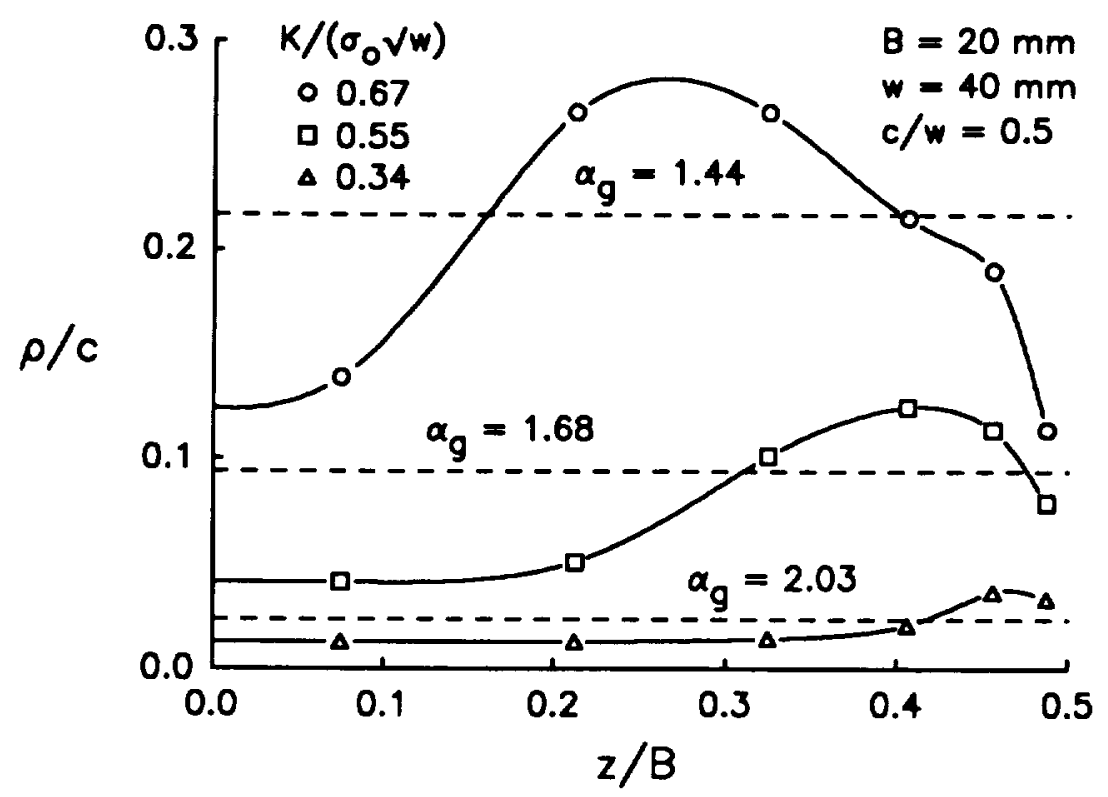

FIG. 13--Plastic-zone size through the thickness for various $K /\left(\sigma_{0} / w\right)$ levels for an $M(T)$ thick plate with $c / w=0.5$.

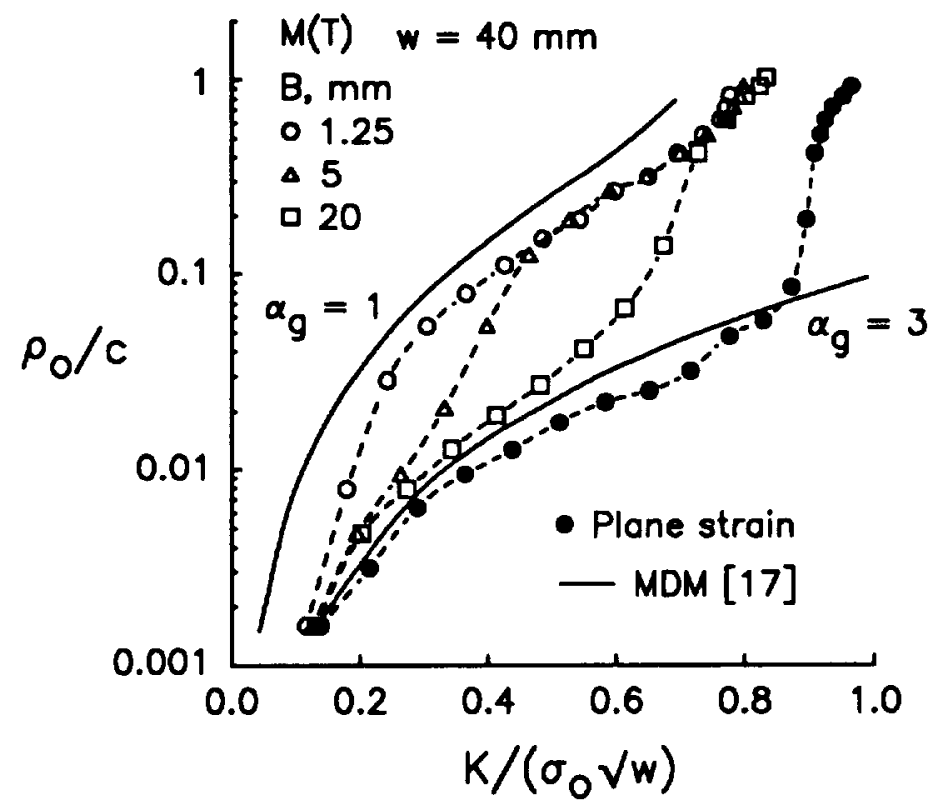

FIG. 14--Mid-plane plastic-zone size against $K /\left(\sigma_{0} / W\right)$ for various $M(T)$ specimen thicknesses and plane strain with $c / w=0.5$. 


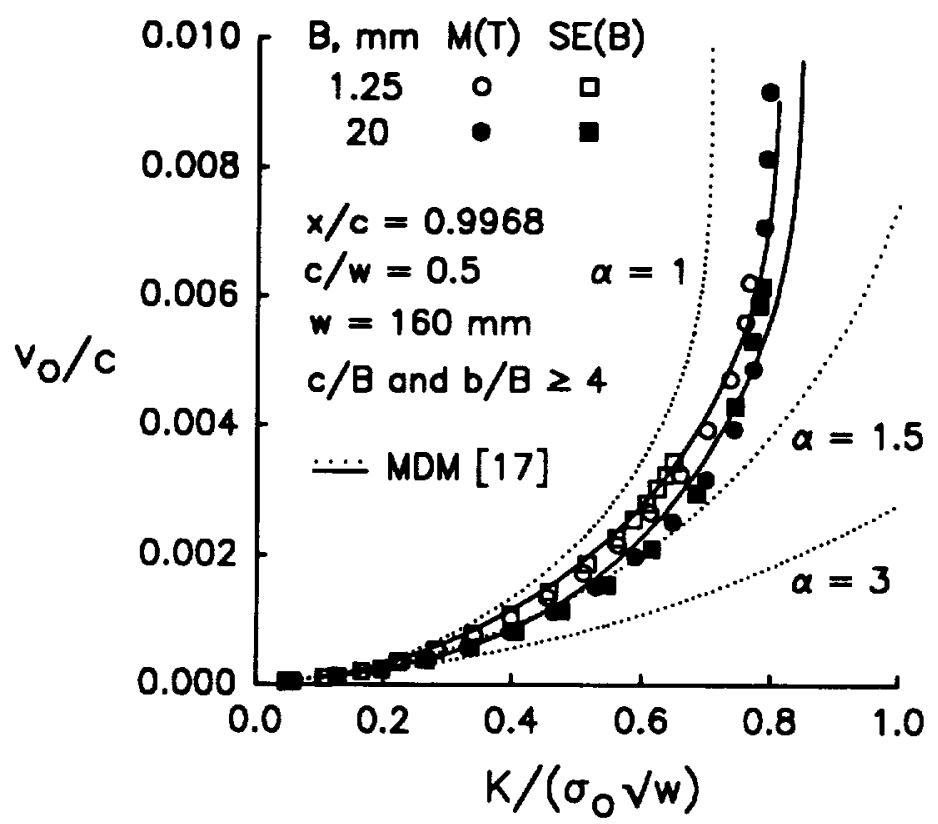

FIG. 15--Mid-plane crack-tip displacements for $M(T)$ and $S E(B)$ specimens with $C / B$ and $b / B$ ratios greater than 4 .

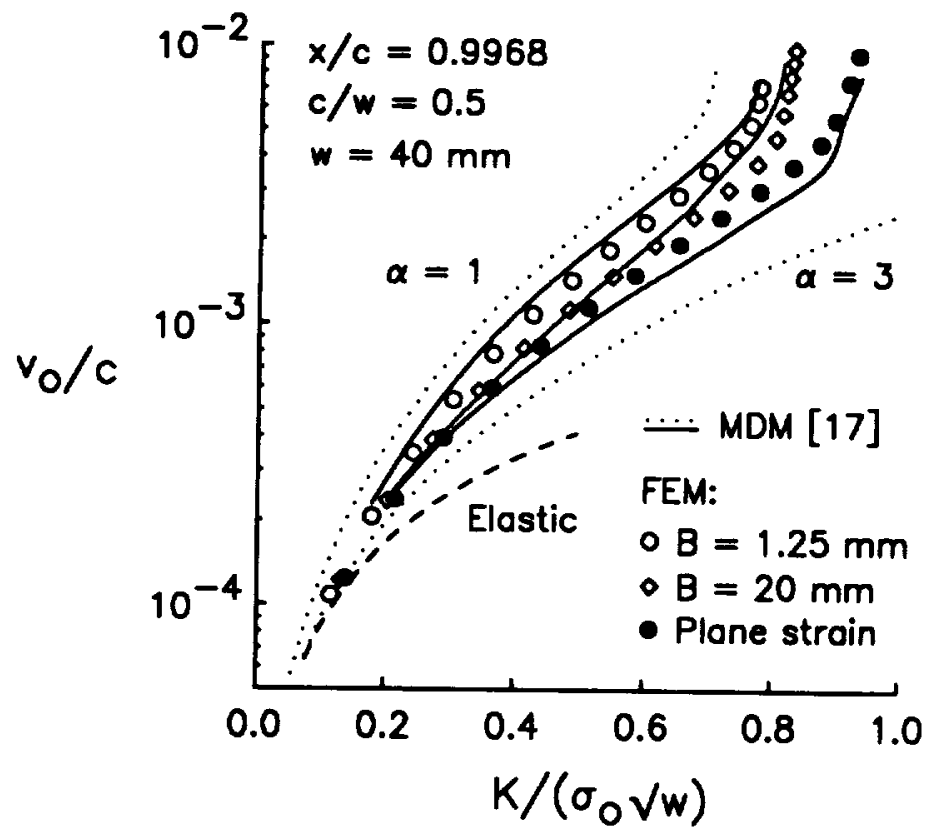

FIG. 16--Mid-plane crack-tip displacements for $M(T)$ specimens with various thicknesses and plane strain. 


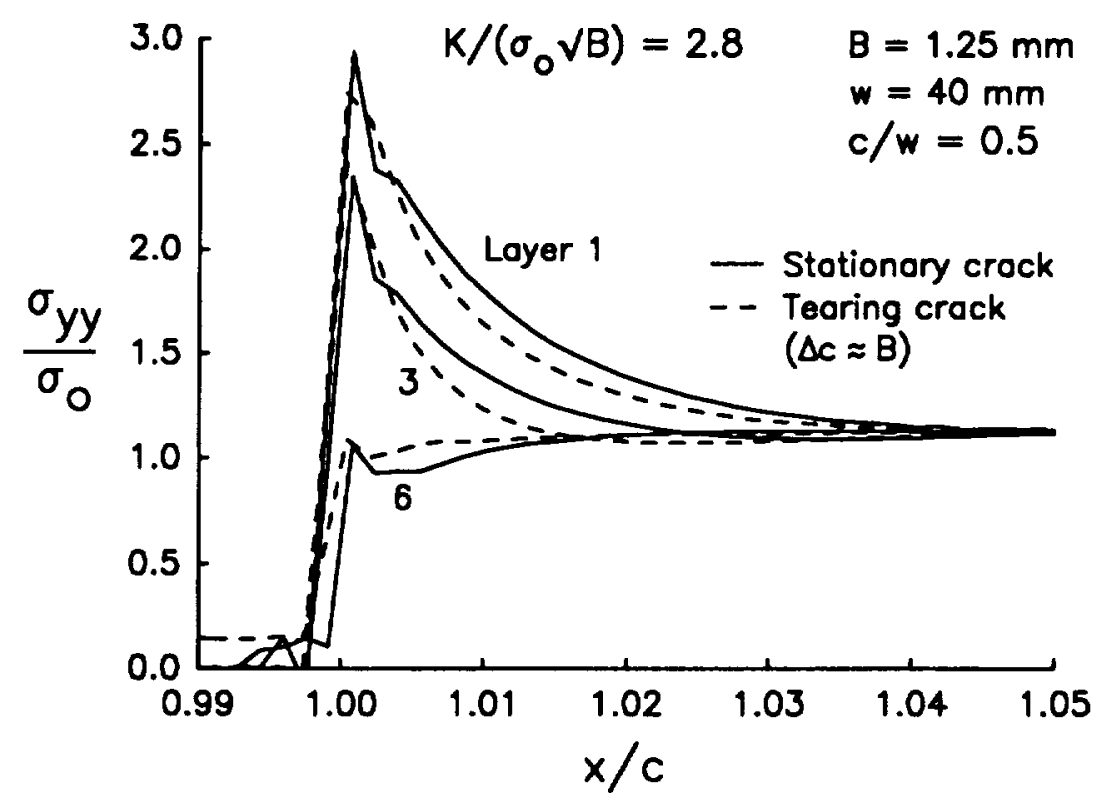

FIG. 17--Normal stresses near crack front in a thin $M(T)$ specimen with a stationary and tearing crack.

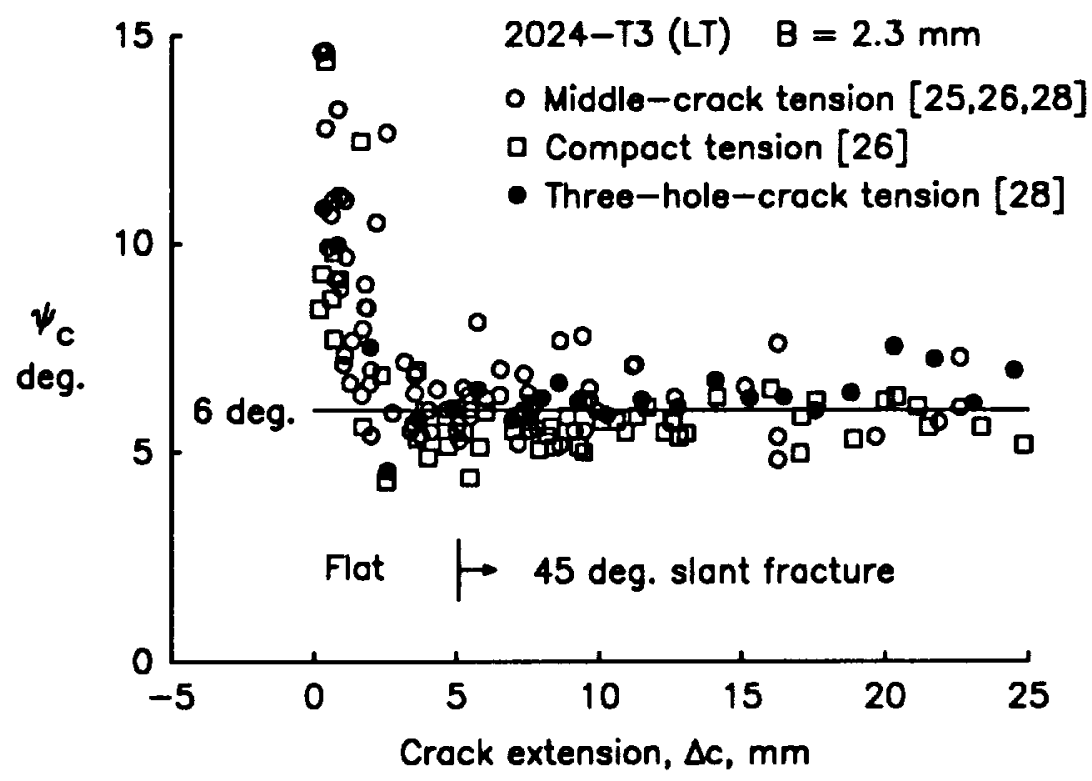

FIG. 18--Comparison of measured critical CTOA values for various specimen types with C/B ratios greater than 4 . 




